\title{
Experimental study on driver seat vibration characteristics of crawler-type combine harvester
}

\author{
Lizhang Xu*, Xiaoyu Chai, Zhipeng Gao, Yaoming Li, Yading Wang \\ (Key Laboratory of Modern Agricultural Equipment and Technology, Ministry of Education; \\ School of Agricultural Equipment and Engineering, Jiangsu University, Zhenjiang 212013, Jiangsu, China)
}

\begin{abstract}
To improve the driving comfort of combine harvesters, driver seat low-frequency vibration and related driver ride-comfort problems were investigated on a Chinese CFFL-850 crawler-type full-feed combine harvester based on ISO2631. Driver vibration and driving seat transmission characteristics were measured under the following conditions: no-load idling, driving on the road, driving in the field, and simulated harvesting. The root mean square values composite vibration under four conditions were $3.63 \mathrm{~m} / \mathrm{s}^{2}, 2.35 \mathrm{~m} / \mathrm{s}^{2}, 3.34 \mathrm{~m} / \mathrm{s}^{2}$, and $2.67 \mathrm{~m} / \mathrm{s}^{2}$, respectively. For the same condition, the maximum root mean square scores of vibration component on driver whole-body occurred in the seat support surface (test point 1) and vertical direction ( $Z$ direction), which were $3.56 \mathrm{~m} / \mathrm{s}^{2}, 2.05 \mathrm{~m} / \mathrm{s}^{2}, 3.15 \mathrm{~m} / \mathrm{s}^{2}$, and $2.43 \mathrm{~m} / \mathrm{s}^{2}$, respectively. The test point 2 to test point 1 vertical-transfer function curve trends were nearly identical. Nearly all of the transfer coefficients were greater than 1 in the range of $1-50 \mathrm{~Hz}$, therefore, the seat vibration attenuation performance was poor. Based on the analysis results, the driver seat structure was altered and a verification test was performed. The test results indicated that after an $X$-damping mechanism was installed, vibration acceleration, on the surface of the seat support under the road-driving conditions, decreased from $2.35 \mathrm{~m} / \mathrm{s}^{2}$ to $1.68 \mathrm{~m} / \mathrm{s}^{2}$. Under the simulated harvesting condition, the vibration acceleration decreased from $2.56 \mathrm{~m} / \mathrm{s}^{2}$ to $1.46 \mathrm{~m} / \mathrm{s}^{2}$. Nearly all of the seat vertical transfer coefficients were less than 1 within the frequency range of 1-80 $\mathrm{Hz}$, therefore the dynamic comfort of the seat was ameliorated after structural improvement.
\end{abstract}

Keywords: crawler-type combine harvester, driver seat, vibration characteristics, ride comfort, damping, structure optimum DOI: $10.25165 /$ j.ijabe. 20191202.3657

Citation: Xu L Z, Chai X Y, Gao Z P, Li Y M, Wang Y D. Experimental study on driver seat vibration characteristics of crawler-type combine harvester. Int J Agric \& Biol Eng, 2019; 12(2): 90-97.

\section{Introduction}

A crawler-type combine harvester is a complex agricultural machine. During operation, the harvester is primarily driven on road surfaces or in fields of crops, which we termed the external factors that contribute to vibration. The engine, cutter, vibrating screen, and reciprocating motion of other parts and the transport tank cylinder are termed the internal factors. The entire machine vibrates substantially at less than $100 \mathrm{~Hz}^{[1-3]}$. The driver seat represents the final component of the vibration transmission. The seat primary function is to support the driver body and dampen the effect of the excitation source, such as the road and the moving parts, on the vibration of the driver body. Thus, the driver seat vibration attenuation performance directly affects driver comfort.

When a general vehicle is operated within its design parameters, the driver seat vibration attenuation is ensured and the driver does not experience discomfort or fatigue caused by vehicle vibration $^{[4,5]}$. However, a crawler-type combine harvester work environment is more complicated than that of a general vehicle. Typically, the harvester is operated in a wet, muddy field. During

Received date: 2017-07-21 Accepted date: 2019-01-07

Biographies: Xiaoyu Chai, $\mathrm{PhD}$ candidate, research interests: harvesting machinery, Email: xfpaxy521123@163.com; Zhipeng Gao, Master, research interests: agricultural machine engineering, Email: 1441012264@qq.com; Yaoming Li, PhD, Professor, research interests: harvesting machinery, Email: ymli@ujs.edu.cn; Yading Wang, Master, research interests: agricultural mechanization, Email: 408994571@qq.com.

*Corresponding author: Lizhang $\mathbf{X u}, \mathrm{PhD}$, researcher, research interests: harvesting machinery. School of Agricultural Equipment Engineering, Jiangsu University, Jiangsu, China. Tel: +86-13815171180; Email: justxlz@126.com. operation, vibration is caused not only by the uneven ground but also by the internal working parts. Typically, the harvester is operated during summer. When temperatures and humidity are high, the operational environment is unfavorable. In addition, to save costs, the driver compartment is typically an open bridge structure. These factors combine to expose the driver of the harvester to a complex vibration environment, resulting in poor comfort. Vibration experts in China and overseas are performing research focused on dynamic performance analysis and vibration testing. Most research focuses on the engine, cutter, and cutting machine as well as the moving parts of the chassis ${ }^{[6-10]}$. Less research has been performed on how driving surfaces affect driver comfort. In contrast, somewhat more research has been performed on the relations between, on the one hand, the tracks, cab, engine, and other machinery and, on the other hand, vibration attenuation and comfort. For example, Nakata et al. ${ }^{[11]}$ analyzed the vibration characteristics of a crawler farm transporter on different road surfaces and according to ISO standards. The effects of two types of rubber track (with and without core) on the vibration attenuation and the influence of vibration on the human body were analyzed. Hostens et al. ${ }^{[12]}$ performed an empirical study on the vibration of combine harvester cabs. The study demonstrated that under high-speed working conditions on a concrete pavement surface, the low-frequency vibration level of the bridge was substantially higher than that of a low-speed driven trawler in a field. In addition, the seat suspension system plays an important role in vibration transmission attenuation. The damping effect of air-spring suspension is substantially better than that of mechanical spring suspension. Deprez et al. ${ }^{[13-16]}$ established a dynamic model of the six degrees of freedom of an agricultural 
machinery cab suspension system. A simulation and experiment validation were performed. As a result, through a reasonable match approach, the stiffness and damping parameters of the cab suspension system and the bridge dynamic thermal comfort were improved. Blood $^{[17]}$ determined the minimum impact on the human body of a vibrating seat. Three different types of city bus driver seats were compared, tested and analyzed under standard road conditions in an evaluation of whole-body vibration. Referring to ISO standards, Kabir et al. ${ }^{[18,19]}$ designed a system to measure the whole-body vibration of an agricultural tractor driver. On four different types of farm roads, vibration measurements were performed at four different tractor speeds to determine the different degrees of tractor working comfort. Wang et al. ${ }^{[20]}$ considered the changing mass of the passengers and sets the total mass of the vehicle seat and human body as an uncertain parameter, established a three degree-of-freedom model, propose the quasi-zero-stiffness vibration isolator as seat suspension to improve vehicle vibration isolation performance. Purnendu et al. ${ }^{[21]}$ provided a simulation model to predict final vibration level inside the human body and car seat to avoid the time consuming and expensive testing methods. It will help understanding the impact and estimation of the vibration level inside the car seat and occupant human body. This study established a foundation for structural improvements to the tractor driver compartment. The cited research, provided references for the improvement of the crawler-type combine harvester driving comfort, presented here.

In this paper, the vibration comfort of a crawler-type full-feed combine harvester was considered based on a comprehensive review of the literature. Current methods of vibration comfort evaluation are summarized. The following international standards served as references: Mechanical Vibration and the Human Body Whole Body Vibration Exposure of ISO 2631, Agricultural wheeled tractor and field machinery: Measurement of whole-body vibration of the operator of GB/T 10910-2004 ${ }^{[22]}$, and Agricultural wheeled tractors - Evaluation criteria of whole body vibration of the operator of GB/T 13876-2007 $7^{[23]}$. Based on these standards, vibration tests and analyses were conducted on the driver seat of a CFFL-850 combine harvester (crawler type; full feed; rubber crawlers with iron cores; the lug pitch is $90 \mathrm{~mm}$ ) and the harvester components related to the driver whole-body vibration. The driver seat vibration attenuation was investigated, and the harvester's vibration comfort was improved.

\section{Material and methods}

\subsection{Experimental object}

The experimental prototype of the crawler-type full-feed CFFL-850 combine harvester, manufactured by Changfa Fengling Agricultural Equipment Co., Ltd, Taizhou, Jiangsu Province, China, included a reel, a cutting and feeding device, a threshing and cleaning device, a straw chopper, a grain bin, a crawler-type driving apparatus and a driver compartment (Figure 1). Main parameters are shown in Table 1.

The harvester driver compartment does not have a closed bridge, and the bridge structure is in open mode. The instrument panel (2) and the left-side console (3) have a rigid connection with the driver compartment floor (10). One end of the driver compartment cover (5) is a rack hinged on the crawler-type driving apparatus (9). The other end is fixed on the left-side console (3) by a connecting lock. The driver seat (4) is joined with the driver compartment cover (5) by a rigid mounting plate connection. The driver compartment lacks a cab or seat suspension, and the driver sits on a cushioned driving seat (4). This seat has a simple structure, with a low cost, and good static characteristics. At more than $100 \mathrm{~Hz}$, the vibration isolation effect is good. However, drivers usually complain that they have varying degrees of low back pain and serious exhaustion.

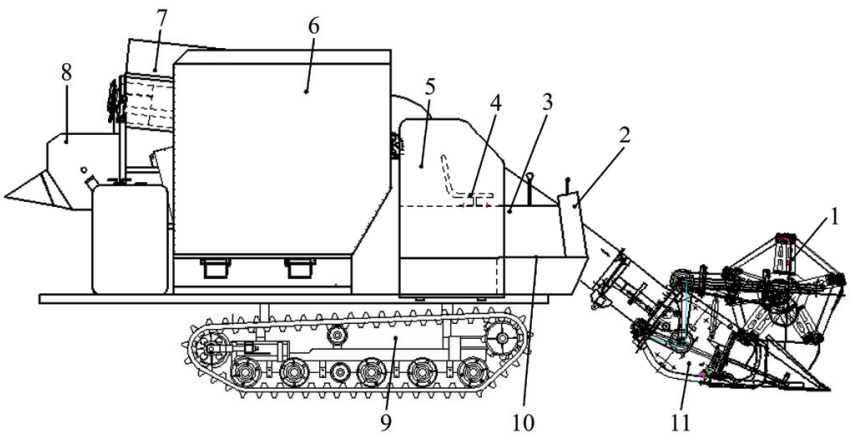

1. Reel 2. Instrument panel 3. Left-side console 4. Driver seat 5. Driver compartment cover 6. Grain bin 7. Threshing and cleaning device 8. Straw chopper 9. Crawler-type driving apparatus 10. Driver compartment floor 11. Cutting and feeding device

Figure 1 Crawler-type CFFL-850 combine harvester

Table 1 Main parameters

\begin{tabular}{lccc}
\hline \multicolumn{1}{c}{ Parameter } & Value & Parameter & Value \\
\hline $\begin{array}{l}\text { Overall dimension } \\
/ \mathrm{mm}\end{array}$ & 2.2 & $\begin{array}{c}\text { The quality of the entire } \\
\text { machine } / \mathrm{kg}\end{array}$ & 2160 \\
$\begin{array}{l}\text { Feed quantity } / \mathrm{kg} \cdot \mathrm{s}^{-1} \\
\text { Driving speed in } \\
\text { field } / \mathrm{m} \cdot \mathrm{s}^{-1}\end{array}$ & $0-1.8$ & $\begin{array}{c}\text { The gap between the chassis } \\
\text { and the ground } / \mathrm{mm}\end{array}$ & 260 \\
Drum & $\begin{array}{c}\text { Longitudinal and } \\
\text { tangential roller }\end{array}$ & $\begin{array}{c}\text { Maximum torque }(\mathrm{N} \cdot \mathrm{m}) / \\
\text { revolution }\left(\mathrm{r} \cdot \mathrm{min}^{-1}\right)\end{array}$ & $360 / 1800$ \\
Engine & CF4C80T & $\begin{array}{c}\text { Rated power }(\mathrm{kW}) / \\
\text { revolution }\left(\mathrm{r} \cdot \mathrm{min}^{-1}\right)\end{array}$ & $63 / 2300$ \\
\hline
\end{tabular}

\subsection{Measurement system}

The measurement system consisted of a testing sensor, a signal acquisition and control system, and a three-part signal analysis and processing system (Figure 2).
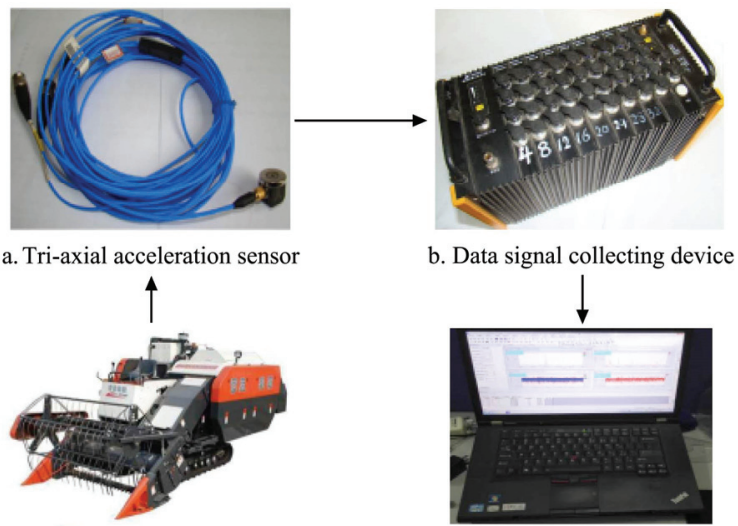

c. Crawler-type CFFL-850 combine harvester d. Signal analysis and processing system

Figure 2 Measurement system hardware block diagram

The signal acquisition instrument was a Jiangsu Donghua DH5902 dynamic signal acquisition system. The system provides 32 digital/analog acquisition channels. The system's AD resolution is 16 , the sampling bandwidth is $100 \mathrm{kHz}$, and the distortion factor is less than $0.5 \%$. The system can be connected to a computer through a cable or WiFi transmitter for data storage and transmission. DHDAS5902-net dynamic signal analysis software, MATLAB software, and a Lenovo ThinkPad were used to analyze the test data. The 356A16 three-way acceleration 
sensors were manufactured by PCB Company. The main equipment technical parameters are shown in Table 2.

Table 2 Test instrument performance parameters

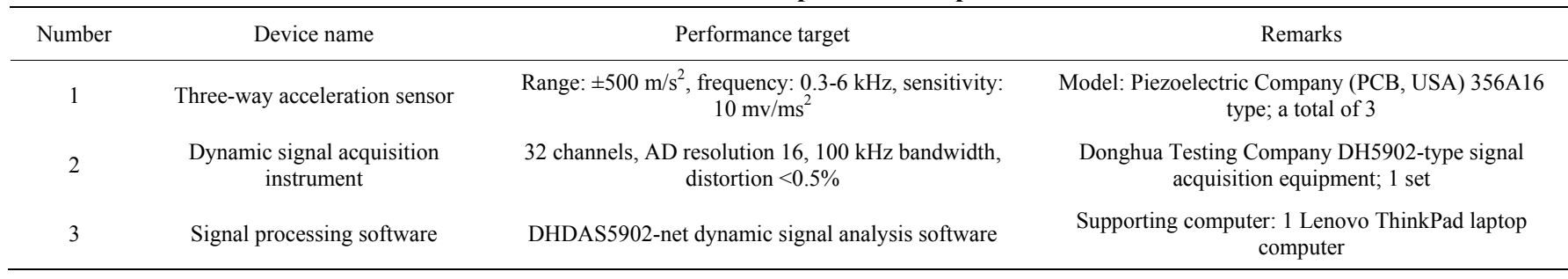

\subsection{Test design}

The tested parameters were the driver body vibration and the driver seat transfer characteristics. The following reference standards were adopted: Mechanical Vibration and the Human Body Whole Body Vibration Exposure of ISO 2631, GB/T10910-2004 related content ${ }^{[22,24,25]}$. The existing experimental condition was considered using a three-point arrangement: seat support surface, beneath the seat mounting plate, and the driver footrest (Figure 3).

The harvester's vibration characteristics were tested under four operating conditions: no-load idling, driving on the road, driving in the field and simulated harvest. The details are provided in Table 3.



Figure 3 Measuring point layout

Table 3 Vibration test design

\begin{tabular}{|c|c|c|c|}
\hline Testing condition & Harvester condition & Accelerator & Ground condition \\
\hline Testing condition 1 & No-load idling (engine operating) & Low throttle (engine speed: $1050 \mathrm{r} / \mathrm{min}$ ) & Cement road \\
\hline Testing condition 2 & Driving on the road (engine and drive tracks operating; moving speed is $1.8 \mathrm{~m} / \mathrm{s}$ ) & High throttle (engine speed: $2100 \mathrm{r} / \mathrm{min}$ ) & Cement road \\
\hline Testing condition 3 & Driving in the field (engine and drive tracks operating; moving speed is $1.1 \mathrm{~m} / \mathrm{s}$ ) & High throttle (engine speed: $2100 \mathrm{r} / \mathrm{min}$ ) & Soft soil \\
\hline Testing condition 4 & Simulation harvest (all harvester components operating; moving speed is $1.1 \mathrm{~m} / \mathrm{s}$ ) & High throttle (engine speed: $2100 \mathrm{r} / \mathrm{min}$ ) & Soft soil \\
\hline
\end{tabular}

Note: "soft soil" refers to non-sloping paddy fields.

\subsection{Test procedure}

Prior to the test, the three measurement points (Figure 3) were cleaned at the testing station. The sensors were then fixed on the corresponding test points in sequence. In addition, the signal-acquisition instrument cables were glued onto the harvester to prevent vibration and impact damage during testing, which might have affected the test result. Finally, the vibration signals of the test points were transferred to the signal-acquisition instrument and the computer via a WiFi transmitter. To obtain an accurate testing waveform, the sampling frequency in the DHDAS5902-net dynamic signal analysis software was set at $2 \mathrm{kHz}$, the analysis frequency at $781.25 \mathrm{~Hz}$, and the frequency domain line number at 1600 . In addition, the mode was continuous sampling, acquisition was freely triggered, and the average method was used for the linear average (the average number was 10; average method can avoid occasionally). When the set-up was complete, the data collection began according to the test conditions described in Table 3. Prior to each sampling, channel reset was used to set the balance. Data collection was performed while the machine was running stably.

\section{Results and analysis}

\subsection{Comfort analysis}

Currently, China has not established combine-harvester comfort evaluation criteria. Therefore, our tests were performed according to the international standard ISO 2631 and GB/T 13876-2007. Under the various operating conditions, the experiment measured three test points. The vibration crest factors were all less than 9. According to the prescribed standards, when the vibration of the crest factor is less than or equal to 9 , the basic evaluation method is generally used to evaluate the vibration.

According to the basic evaluation method, the vibration of the seat's bearing surface, the driver footrest, the $X$ direction (i.e., the forward movement of the harvester), the $Y$ direction (i.e., movement from the center to the left side of the harvester), the $Z$ direction (i.e., the vertical movement of the harvester), and the root mean square acceleration of the three directions were calculated as follows:

$$
a_{w}=\left[\sum_{i=1}^{n}\left(W_{i} \cdot a_{i}\right)^{2}\right]^{1 / 2}
$$

where, $i$ is the order number of octave band; $w$ indicate that it is weighted RMS acceleration; $W_{i}$ is the $1 / 3$ octave band weighting coefficient of $i$ (Table 4; GB/T1344.1-2007 $7^{[26]}$ ); $a_{i}$ is the $1 / 3$ octave band acceleration root mean square value of $i$, which was analyzed and calculated using the DHDAS5902 octave dynamic signal analysis software. Next, we calculated the vibration of the seat-bearing surface and the driver footrest as follows:

$$
a_{v j}=\left(k_{x}{ }^{2} a_{w x}{ }^{2}+k_{y}{ }^{2} a_{w y}{ }^{2}+k_{z}{ }^{2} a_{w z}{ }^{2}\right)^{1 / 2}
$$

where, $j=1$ represents the seat-bearing surface test point and $j=3$ represents the driver footrest test point; $a_{w x}, a_{w y}$, and $a_{w z}$ correspond to the weighted root mean square acceleration in the $X, Y$, and $Z$ directions, respectively; $k_{x}, k_{y}$, and $k_{z}$ represent the three directions of the direction factor. According to ISO2631-1-1997 regarding the seat support surface, the values of $k_{x}$ and $k_{y}$ should be 1.4 and the value of $k_{z}$ should be 1 . Regarding the driver footrest, the values of $k_{x}$ and $k_{y}$ are 0.25 and the value of $k_{z}$ is 0.4 . Finally, to determine the multi-point vibration comfort, we calculated the total 
integrated vibration $a_{v}$ as follows:

$$
a_{v}=\left(\sum a_{v j}\right)^{1 / 2}
$$

According to ISO 2631-1-1997, the relationship between weighted acceleration and subjective body feeling is as shown in Table 4. Based on the nature of the work and the harvester's structure, the driver whole-body vibration limit evaluation index is as recommended by GB/T $13876-2007^{[23]}$. The belt-drive tractor limit value was set at $3.5 \mathrm{~m} / \mathrm{s}^{2}$.

Table 4 Relationship between subjective evaluation and objective evaluation

\begin{tabular}{cc}
\hline Weighted acceleration value & Subjective experience of human body \\
\hline$<0.315$ & Very comfortable \\
$0.315-0.63$ & Fairly comfortable \\
$0.5-1.0$ & Less comfortable \\
$0.8-1.6$ & Not comfortable \\
$1.25-2.5$ & Uncomfortable \\
$>2.0$ & Very uncomfortable \\
\hline
\end{tabular}

The amplitude of vibration acceleration at test points 1 and 3 were calculated using Equations (1)-(3) and analyzed using MATLAB. The results are shown in Table 5.

Table 5 Vibration results for two test points under different conditions

\begin{tabular}{|c|c|c|c|c|c|c|c|c|c|}
\hline \multirow{2}{*}{$\begin{array}{l}\text { Operating } \\
\text { condition }\end{array}$} & \multicolumn{4}{|c|}{ Test point 1} & \multicolumn{4}{|c|}{ Test point 3} & \multirow{2}{*}{$\begin{array}{c}a_{v} \\
/ \mathrm{m} \cdot \mathrm{s}^{-2}\end{array}$} \\
\hline & $X$ & $Y$ & $Z$ & $a_{v 1}$ & $X$ & $Y$ & $Z$ & $a_{v 3}$ & \\
\hline 1 & 0.32 & 0.23 & 3.56 & 3.60 & 0.37 & 0.41 & 1.03 & 0.43 & 3.63 \\
\hline 2 & 0.36 & 0.32 & 2.05 & 2.16 & 0.69 & 0.86 & 2.79 & 1.15 & 2.35 \\
\hline 3 & 0.41 & 0.51 & 3.15 & 3.28 & 0.79 & 0.87 & 1.42 & 0.64 & 3.34 \\
\hline 4 & 0.39 & 0.43 & 2.43 & 2.56 & 0.77 & 1.40 & 1.60 & 0.75 & 2.67 \\
\hline
\end{tabular}

Based on Table 4 and Table5, the following statements can be made:

1) The harvester's composite vibration totals (root mean square values) for the four operating conditions (no-load idling, driving on the road, driving in the field and simulated harvest) were $3.63 \mathrm{~m} / \mathrm{s}^{2}$, $2.35 \mathrm{~m} / \mathrm{s}^{2}, 3.34 \mathrm{~m} / \mathrm{s}^{2}$, and $2.67 \mathrm{~m} / \mathrm{s}^{2}$, respectively. When the harvester was exposed to the no-load idling condition (operating condition 1), the total integrated vibration was the largest, at $3.63 \mathrm{~m} / \mathrm{s}^{2}$, which exceeds the recommended $3.5 \mathrm{~m} / \mathrm{s}^{2}$ limit. When driving in the field (operating condition 3), the total integrated vibration was $3.34 \mathrm{~m} / \mathrm{s}^{2}$, which is close to the recommended limit value. Under the simulated harvest condition (operating condition 4) and, the driving on the road condition (operating condition 2), the root mean square values were the lowest, at $2.67 \mathrm{~m} / \mathrm{s}^{2}$ and $2.35 \mathrm{~m} / \mathrm{s}^{2}$, respectively, within the recommended limits.

2) Under the four operating conditions, the seat support surface (test point 1) total vibration values were $3.60 \mathrm{~m} / \mathrm{s}^{2}, 2.16 \mathrm{~m} / \mathrm{s}^{2}$, $3.28 \mathrm{~m} / \mathrm{s}^{2}$ and $2.56 \mathrm{~m} / \mathrm{s}^{2}$, respectively. The total vibration values of the driver footrest (test point 3) were $0.43 \mathrm{~m} / \mathrm{s}^{2}, 1.15 \mathrm{~m} / \mathrm{s}^{2}$, $0.64 \mathrm{~m} / \mathrm{s}^{2}$ and $0.75 \mathrm{~m} / \mathrm{s}^{2}$, respectively. Comparing the total vibration of test point 1 with that of test point 3 , we found for each operating condition that total vibration of test point 1 was greater than that of test point 3 . This outcome suggests that the vibration influence of the bearing surface area on the driver is greater than the vibration of the driver footrest.

3) For each operating condition, the driver whole-body root mean square value vibration component maximum score, occurred in the seat support surface (test point 1 ) vertical direction $(\mathrm{Z}$ direction): $3.56 \mathrm{~m} / \mathrm{s}^{2}, 2.05 \mathrm{~m} / \mathrm{s}^{2}, 3.15 \mathrm{~m} / \mathrm{s}^{2}$, and $2.43 \mathrm{~m} / \mathrm{s}^{2}$, respectively. For each operating condition, the vertical direction score was substantially larger than that of the other two directions. This outcome indicates that the influence of the driver seat vertical vibration on the whole-body vibration was greater than the transverse and axial vibrations.

4) Contrasting Table 4 with Table 5 shows that under each operating condition, the operator's driving experience varies from very uncomfortable to uncomfortable. In conclusion, the driving comfort is poor, specifically, when the harvester is set in the no-load idle operating condition (operating condition 1), thus the driver has the worst subjective feeling. Under the field driving condition (operating condition 3), the driver comfort is somewhat better.

5) Based on the preceding comprehensive analysis, under the various operating conditions, the harvester driver body vibration values are higher and the harvester's vibration comfort is very poor. The total vibration of the seat support surface (test point 1) and the driver footrest (test point 3 ) is 1.9-8.4 times of the recommended value, and the contribution of test point 1 to the driver whole-body vibration is larger. In addition, the vibration of the test point 1 in $Z$ direction is 5.7-11.1 times of that in $X$ direction and 5.7-15.5 times of that in $Y$ direction. This outcome indicates that the seat's vertical vibration is the primary cause of poor driver vibration comfort. This phenomenon may occur because the driver seat vibration attenuation performance is poor. Therefore, we analyzed the driver seat transfer characteristics (i.e., vibration transfer from test point 2 to test point 1 ), particularly the vertical transfer characteristics.

\subsection{Seat transfer characteristics analysis}

Based on the theory of transfer function, the vibration transfer function is defined as follows:

$$
H(f)=\frac{Y(f)}{X(f)}
$$

where, $H(f)$ is the system transfer function; $Y(f)$ is the Fourier transform of system output $Y(t)$, and $X(f)$ is the Fourier transform of system input $X(t) . \quad Y(f)$ refers to the frequency domain function of test point 1 , and $X(f)$ refers to the frequency domain function of test point 2.

For processing, the $1 / 3$ octave band segment analysis method was used, which is appropriate for human-body vibration evaluation. That is, the $1 / 3$ octave band divides the system energy into output $Y(f)$ and input $X(f)$ energy. The energy value range is $1-80 \mathrm{~Hz}$. Next, the average of each band's energy is adopted as the center frequency energy. Then, we divide each of the center frequency $Y(f)$ and $X(f)$ values to obtain a relevant ratio score. Finally, we connect each ratio point and perform curve fitting to create a graph of the transfer coefficient.

Driving on the road (operating condition 2), driving in the field (operating condition 3 ), and simulated harvest (operating condition 4) are typical operating conditions. To determine the seat's $Z$ direction (i.e., vertical) vibration transfer characteristics, we used the $1 / 3$ octave band segment analysis method for data processing in order to obtain the vertical transfer function curves (test point 2 to test point 1 ) of the three operating conditions (Figure 4 ).

Based on Figures 4a-4c, the following statements can be made:

1) When driving on the road (operating condition 2), at a frequency range of less than $47 \mathrm{~Hz}$, the test point 2 to test point 1 transfer coefficient was greater than 1 . At $47-80 \mathrm{~Hz}$, the transfer coefficient was less than 1 . At the center frequency of the $1 / 3$ octave band $(25 \mathrm{~Hz})$, the transfer coefficient reached a maximum value. These outcomes indicate that for the prototype seat in the 
human body's sensitive range of 1-80 Hz, the damping effect is not good, particularly near the $25 \mathrm{~Hz}$ frequency band, where the transfer coefficient was greater than 2.5. We concluded that the investigated spectrum would easily cause the prototype seat to resonate.

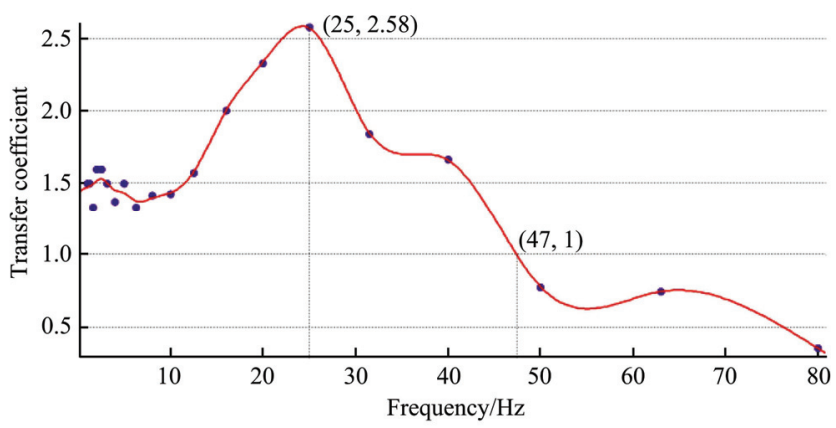

a. Vertical transfer function of operating condition 2

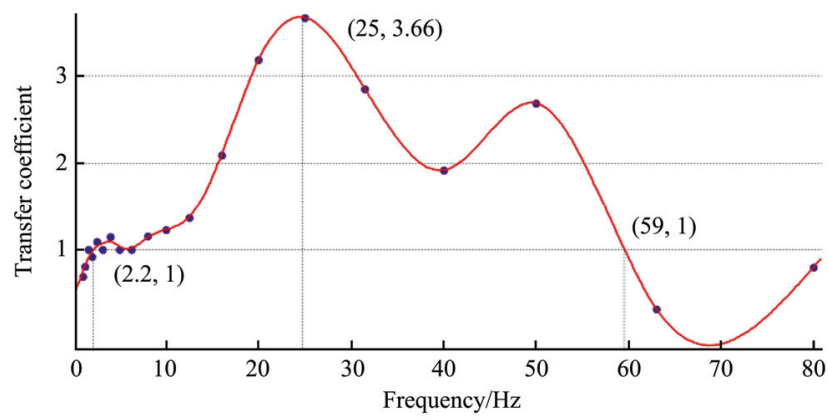

b. Vertical transfer function of operating condition 3

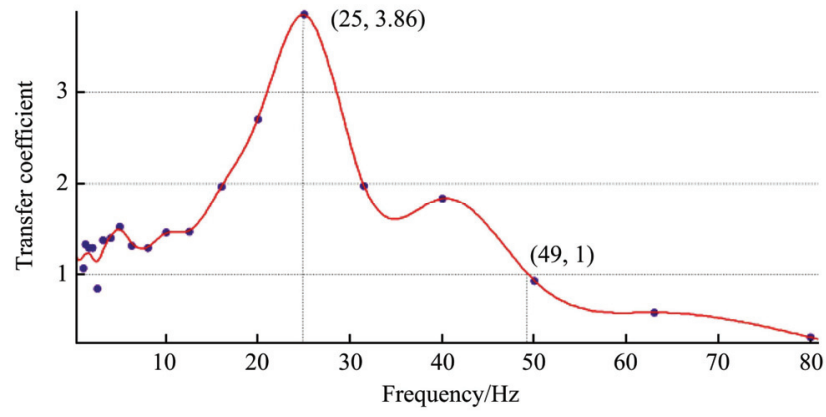

c. Vertical transfer function of operating condition 4

Figure 4 Vertical transfer functions of three typical operating conditions (based on the 1/3 octave band method)

2) When driving in the field (operating condition 3), the test point 2 to test point 1 transfer coefficient in the $2.2-59 \mathrm{~Hz}$ frequency range was greater than 1 . The frequency ranges of 20-30 Hz and 40-60 Hz exhibited high peak values: scores between 2-4. The maximum transfer coefficient value appeared in the center frequency of the $1 / 3$ octave band $(25 \mathrm{~Hz})$.

3) During simulated harvest (operating condition 4), regarding vibration transfer from test point 2 (i.e., the seat's mounting plate) to test point 1 (i.e., the seat's bearing surface), the transfer coefficient in the $1 / 3$ octave band centered frequency range (approximately $25 \mathrm{~Hz}$ ) attained a maximum value. In addition, when the frequency was in the less than $49 \mathrm{~Hz}$, the transfer coefficient was greater than 1 . These outcomes indicate that the prototype seat did not serve the intended purpose of attenuating vibration and, contrary to expectations, had a vibration amplification effect.

4) Under the previously described three operating conditions, regarding vibration transfer from test point 2 to test point 1 , the vertical transfer function curve trend generally remained the same and the maximum values appeared at the center frequency of the
$1 / 3$ octave band $(25 \mathrm{~Hz})$. Therefore, we can conclude that the prototype seat's vibration mode, vertical vibration natural frequency, should be a certain value and within the frequency band. In addition, within the frequency range of $1-50 \mathrm{~Hz}$, nearly all of the seat transfer coefficients were greater than 1. This outcome indicates that within the frequency bands to which humans are sensitive, the seat's vibration attenuation performance is poor. Thus, an urgent need to improve the seat structure, particularly its suspension system, was revealed.

\subsection{Seat structure improvement}

\subsubsection{Seat suspension structure improvement}

Based on a comprehensive consideration of the work environment and suspension mechanism production costs, an $X$-type mechanical damping mechanism was designed with reference to the HY-04 scissor seat (Figure 5).

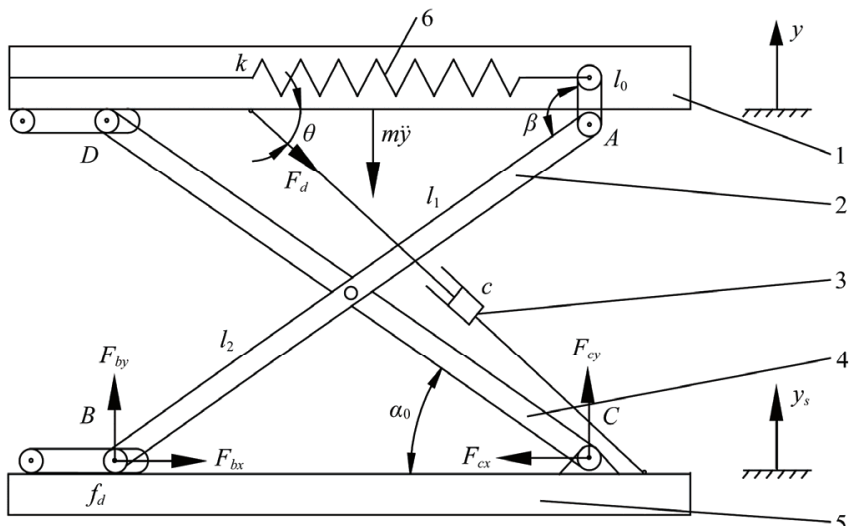

1. Base plate connection 2. Bar I 3. Damper 4. Bar II 5. Under-floor connection 6. Stretch spring

Figure 5 Seat suspension structure force diagram

This suspension mechanism primarily consists of a base-plate connection, an under-floor connection, bar I (2), bar II (2), a stretch spring (2) and a hydraulic damper.

The base-plate connection and the under-floor connection articulate in the form of an $X$-shaped support mechanism with a cut-stem connection. The upper end of bar I articulates with a connection on the base plate. The lower end is a horizontal slide in the left chute of the under-floor connection. The lower end of bar II articulates with the under-floor connection. The upper end is a horizontal slide in the left chute of the base-plate connection. The spring (6) is a linear spiral spring with stiffness $k$. One end is connected with bar I's upper end. The other end is connected with the seat suspension's left-upper endpoint. The damper (3) is installed at an angle between the upper and lower connection plates. The damping coefficient is $c . \quad \alpha_{0}$ is the angle between bar II and the under-floor connection under the action of the seat (with mass $m$ ) when held in a static equilibrium position. $l_{0}, l_{1}$ and $l_{2}$ represent each partial length of the cut rod. $\beta$ is the fixed angle between the upper end of bar I, the articulated point position $\left(l_{0}\right.$ section) and the main part of bar I ( $l_{1}$ and $l_{2}$ sections).

Studies ${ }^{[27,28]}$ have demonstrated that for isolation suspension to achieve satisfactory vibration isolation at a low vibration frequency, the suspension system natural frequency $f_{n}$ must be decreased. In addition, sufficient stiffness $c$ should be provided to limit the excessive vibration damping peak. The balance equation can be established by the D'Alembert's principle, as shown in Equation (5):

$$
\left\{\begin{array}{l}
\sum X=0, \quad F_{c x}-F_{b x}-F_{d x} \cos (\theta+\Delta \theta)=0 \\
\sum Y=0, \quad F_{c x}-F_{b x}-F_{d} \sin (\theta+\Delta \theta)=0 \\
\sum M=0, \quad 2 F_{b x} l_{2} \cos (\theta+\Delta \theta)-m \cos (\theta+\Delta \theta)=0
\end{array}\right.
$$


where, $F_{d}=c\left(y-y_{s}\right) \sin (\theta+\Delta \theta), \Delta \theta$ is the change of the damper inclination under the excitation: $F_{b x}=f_{d} F_{b y}$

Based on the theory of vibration ${ }^{[29-31]}$, the natural frequency of the suspension $\operatorname{system} f_{n}$ :

$$
f_{n}=\frac{l_{0}}{2 \pi L}\left(\sin \beta-\cos \beta \tan \alpha_{0}\right) \sqrt{\frac{k}{m}}
$$

In Equation (6), $L=l_{1}+l_{2}$ and $m$ represents the equivalent sprung mass, or the sum of the body mass and seat suspension (upper quality: $75 \%$; in the vertical direction).

Commonly, the damping ratio $\zeta$ is used to evaluate damping:

$\zeta=$

$$
\frac{c\left[\left(l_{2}-l_{1}\right)\left(\sin 2 \theta-2 f_{d} \sin ^{2} \theta\right)+\tan \alpha_{0}-l_{0}\left(2 \sin ^{2} \theta-f_{d} \sin 2 \theta \tan ^{2} \alpha_{0}\right)\right]}{4 l_{0}\left(f_{d} \tan \alpha_{0}-1\right)\left(\sin \beta-\cos \beta \tan \alpha_{0}\right) \sqrt{k m}}
$$

In Equation (7), $c$ is the damping coefficient, $f_{d}$ is the sliding friction coefficient, $k$ is the spring stiffness, and $m$ is the sprung mass.

As Equations (6) and (7) indicated, the seat suspension system's inherent frequency $f_{n}$ depends on spring stiffness $k$, sprung equivalent mass $m$, the angle between bar II and the under-floor connection held in static equilibrium position $\alpha_{0}$, and cut-stem geometric parameters $l_{0}, \beta$ and $L$. Damping ratio $\zeta$ depends on


a. Suspension structure physical structure damper damping coefficient $c$, spring stiffness $k$, sprung equivalent mass $m$, and the angle between bar II and the under-floor connection held in static equilibrium position $\alpha_{0}$. Based on this comprehensive consideration, the seat size and installation parameters, the cut-rod geometric parameters and the installation angle under static equilibrium are shown in Table 6 .

Table 6 Suspension geometry parameter values when at static equilibrium position

\begin{tabular}{cccccc}
\hline$l_{0} / \mathrm{mm}$ & $l_{1} / \mathrm{mm}$ & $l_{2} / \mathrm{mm}$ & $\beta /\left({ }^{\circ}\right)$ & $\theta /\left({ }^{\circ}\right)$ & $\alpha_{0} /\left(^{\circ}\right)$ \\
\hline 50.0 & 100.0 & 150.0 & 120.0 & 22.0 & 11.0 \\
\hline
\end{tabular}

Based on these geometric parameters, the lower the spring stiffness, the lower the natural frequency will be. However, spring stiffness cannot be decreased haphazardly and generally should not be less than $3 \mathrm{kN} / \mathrm{m}$. In this test, the selected spring stiffness is $200 \mathrm{kN} / \mathrm{m}$ and the recommended damping ratio is 0.3-0.5. Increased damping would be better. Using Equation (6), we can calculate the value of $c$ for $2163-3605 \mathrm{~N} / \mathrm{s} \cdot \mathrm{m}$. Thus, for the damper selected for this test, the damping coefficient is $3500 \mathrm{~N} / \mathrm{s} \cdot \mathrm{m}$.

Figure 6a shows the seat suspension's physical diagram. The suspension mechanism was provided with seat cushions and installed on the harvester in the original driver seat location. The modified seat structure is shown in Figure 6b.


b. Improved seat structure and post-installation image

Figure 6 Seat suspension structure

\subsubsection{Pre- and post-optimization comparison}

After optimization, we measured vibration at the driver seat (test point 1 ) and under the seat's mounting plate (test point 2 ). The test operating conditions were driving on the road and simulated harvest, which are typical operating conditions. The test process was the same as previously described. The measurement data was subjected to FFT transform, and calculations were performed according to Equations (1) to (3). The weighted root mean square acceleration was obtained for test point 1 under both operating conditions (Table 7). Using the 1/3

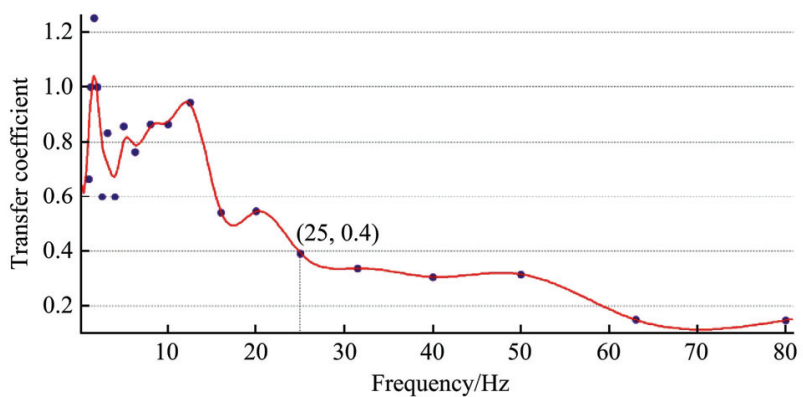

a. Seat vertical transfer coefficient under road driving condition octave band segment method, the test point 2 to test point 1 transfer function was analyzed. In this manner, we created a graph of the seat system's vertical transfer function for the two operating conditions (Figure 7).

Table 7 Point 1 before and after optimization (unit: $\mathrm{m} / \mathrm{s}^{2}$ )

\begin{tabular}{lccc}
\hline Operating condition & $\begin{array}{c}a_{v 1} \text { (Before } \\
\text { optimization) }\end{array}$ & $\begin{array}{c}a_{v 2} \text { (After } \\
\text { optimization) }\end{array}$ & $\begin{array}{c}\text { Improvement effect } \\
\text { (reduce percentage) } \%\end{array}$ \\
\hline Driving on the road & 2.35 & 1.68 & 28.50 \\
Simulated harvest & 2.56 & 1.46 & 42.90 \\
\hline
\end{tabular}

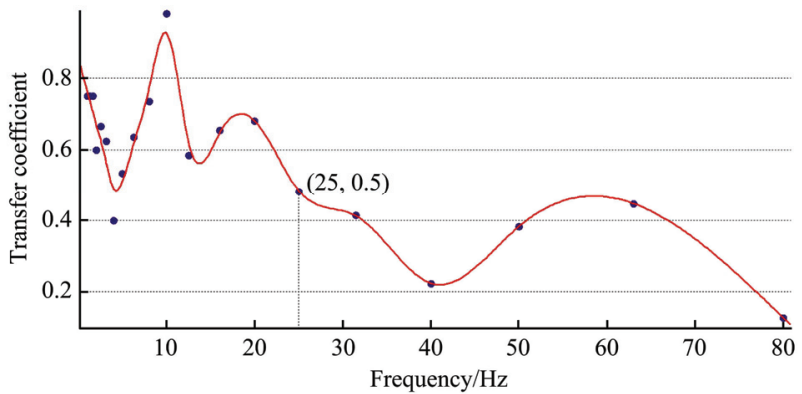

b. Seat vertical transfer coefficient under simulated harvest condition

Figure 7 Driver seat vertical transfer function after improvement 
Based on Table 7 and Figure 7, we can offer the following conclusions:

1) Regarding the post-modification seat structure, the weighted root mean square acceleration at test point 1 under the, driving on the road condition, was $1.68 \mathrm{~m} / \mathrm{s}^{2}$. This outcome represents a decrease of $0.67 \mathrm{~m} / \mathrm{s}^{2}$ compared with the pre-improvement value of $2.35 \mathrm{~m} / \mathrm{s}^{2}$ (28.50\% decreased). Under the simulated harvest working condition, the mean square acceleration was $1.46 \mathrm{~m} / \mathrm{s}^{2}$. This outcome represents a decrease of $1.1 \mathrm{~m} / \mathrm{s}^{2}$ compared with the pre-improvement value of $2.56 \mathrm{~m} / \mathrm{s}^{2} \quad(42.90 \%$ decreased $)$. Therefore, after structural modification, seat comfort improved.

2) After structure modification, for the two typical operating conditions, nearly all of the seat's vertical transfer coefficients were less than 1 in the frequency range of $1-80 \mathrm{~Hz}$, particularly in the frequency range of $25-80 \mathrm{~Hz}$, where the transfer coefficient was less than 0.5 . Vibration damping transfer to the seat's bearing surface had an obvious effect. The results indicate that the vibration attenuation mechanism performs well and can substantially attenuate the vibration transfer to the seat.

3) The weighted root mean square acceleration and seat transfer coefficient decreased. This outcome indicates that after the seat suspension structure was optimized, the driver seat dynamic comfort improved. Thus, the feasibility and effectiveness of the seat suspension structure optimization are demonstrated.

\section{Conclusions}

1) Based on the analysis of CFFL- 850 harvester's vibration level and driver comfort, the combine harvester exhibits poor comfort under various typical operating conditions. The up-down vibration of the driver seat bearing surface has the largest effect on driver body vibration. This outcome suggests that vertical vibration is the primary cause of the driver seat poor vibration comfort.

2) Using a prototype seat, a vertical vibration transfer characteristics analysis was performed. In the 1-50 Hz frequency range, nearly all of the vertical transfer coefficients were greater than 1. The maximum value occurred in the $1 / 3$ octave band center frequency of $25 \mathrm{~Hz}$. This outcome indicates that in frequency bands to which humans are sensitive, the driver seat vibration attenuation performance was poor. Therefore, amelioration of the seat structure was required, particularly the suspension system.

3) The original seat structure was improved, and a vibration test was performed. The test results indicate that an X-shear-type mechanical vibration attenuation mechanism performs better than the original seat. The effect of vibration damping transfer on the driver seat bearing surface was obvious. The driver seat dynamic comfort was improved, and the effectiveness of the structural improvement of the seat suspension was demonstrated.

\section{Acknowledgments}

This research was supported by the National Natural Science Foundation of China (51475217), the Fok Ying-Tong Education Foundation of China (Grant No. 141051), Six Talent Peaks Project in Jiangsu Province (NY-024) and a project funded by the Priority Academic Program Development (PAPD) of Jiangsu Higher Education Institutions. We greatly appreciate the anonymous reviewers for their constructive comments to improve our manuscript.

\section{[References]}

[1] Jiang L. Research on vibration test of combine harvester. Agricultural Machinery, 2011; 4: 119-120. (in Chinese)

[2] Wang B, Liu F, Li Y W. Development status and development trend of rice harvester in China. Agricultural Mechanization Research, 2013; 10: 226-229. (in Chinese)

[3] Xu L Z, Li Y M, Sun P P, Pang J. Vibration test and analysis of crawler type full feed rice combine harvester. Transactions of the CSAE, 2014; 30(8): 49-54. (in Chinese)

[4] Deng B B. Evaluation method of automotive vibration ride comfort. Hefei: Hefei University of Technology, 2005. (in Chinese)

[5] Huang B, Jiang Z H, Yan J Q. Research on dynamic comfort of automobile seat system. Automotive Science and Technology, 2006; 6: 13-16. (in Chinese)

[6] Pang F b, Meng F C, Fang Y P. Study on vibration isolation system of a 3060 combine engine. Transactions of the CSAM, 2000; 31(6): 72-74. (in Chinese)

[7] Reza E, Mohsen E, Saeed Z. Vibration modeling and modification of cutting platform in a harvest combine by means of operational modal analysis (OMA). Measurement, 2013; 46: 3959-3967.

[8] Takashi F, Eiji I. Vibration characteristics and modeling of knife driving system of combine harvester, part 1: Frequency resolution of time series by wavelet analysis. Journal of the Japanese Society of Agricultural Machinery, 2006; 68: 52-58.

[9] Takashi F, Eiji I. Collision vibration characteristics with interspace in knife driving system of combine harvester. Engineering in Agriculture, Environment and Food, 2012; 5(3): 115-120.

[10] Fukushima T, Inoue E, Mitsuoka M, Okayasu T, Sato K. Collision vibration characteristics with interspace in knife driving system of combine harvester. Engineering in Agriculture, Environment and Food, 2012; 5: $115-120$.

[11] Nakata T, Sogabe Y, Araki T. Vibration property of a rubber crawler system when traveling over bumps. Engineering in Agriculture, Environment and Food, 2010; 3: 47-53.

[12] Hostens I, Ramon H. Descriptive analysis of combine cabin vibrations and their effect on the human body. Journal of Sound and Vibration, 2003; 266: 453-464.

[13] De Temmerman J, Deprez K, Hostens I. Conceptual cab suspension system for a self-propelled agricultural machine, part 2: Operator comfort optimization. Biosystems Engineering, 2005; 90: 271-278.

[14] De Temmerman J, Deprez K, Anthonis J, Ramon H. Conceptual cab suspension system for a self-propelled agricultural machine, part 1: Development of a linear mathematical model. Biosystems Engineering, 2004; 89: 409-416.

[15] Deprez K, Moshou D, Ramon H. Comfort improvement of a nonlinear suspension using global optimization and in situ measurements. Journal of Sound and Vibration, 2005; 284: 1003-1014.

[16] Deprez K, Moshou D, Anthonis J, De Baerdemaeker J, Ramon H. Improvement of vibrational comfort on agricultural vehicles by passive and semi-active cabin suspensions. Computers and Electronics in Agriculture, 2005; 49: 431-440.

[17] Blood R P, Ploger J D, Yost M G, Ching R P, Johnson R P. Whole body vibration exposures in metropolitan bus drivers: A comparison of three seats. Journal of Sound and Vibration, 2010; 329: 109-120.

[18] Kabir M S N, Chung S, Kim Y, Shin S. Comparison of test standards for performance and safety of agricultural tractors. Journal of Biosystems Engineering, 2014; 39: 158-165.

[19] Kabir M S N, Ryu M, Chung S, Kim Y, Choi C, Hong S, Sung J. Research trends for performance, safety, and comfort evaluation of agricultural tractors. Journal of Biosystems Engineering, 2014; 39: 21-33.

[20] Wang Y, Li S, Cheng C, Su Y. Adaptive control of a vehicle-seat-human coupled model using quasi-zero-stiffness vibration isolator as seat suspension. Journal of Mechanical Science \& Technology, 2018; 32(7): 2973-2985. (in Chinese)

[21] Purnendu M, Arunachalam S. Vibration study in human-car seat system: overview and a novel simulation technique. Journal of Material Sciences \& Engineering, 2018; 7: 421.

[22] GB/T 10910. Agricultural wheeled tractor and field operation mechanical driver whole body vibration measurement. Standards Press of China, 2004

[23] GB/T 13876. Agricultural wheeled tractor driver whole body vibration evaluation index. Standards Press of China, 2007 
[24] ISO 10326-1. Mechanical vibration - Laboratory method for evaluating vehicle seat vibration. Geneva, Switzerland: ISO. 1992

[25] ISO 2631-1. Mechanical vibration and shock. Geneva, Switzerland: ISO. 1997

[26] GB/T 13441.1. Mechanical vibration and shock-Evaluation of human exposure to whole-body vibration, Part 1: General requirements. Standards Press of China, 2007

[27] Liu Y H. Design and comfort analysis on engineering vehicle seat. Nanchang: China East Jiaotong University, 2013. (in Chinese)
[28] Zou J L, Qian Z J, Zhou Y M. Study on small tractor driving seat structure. Beijing Agricultural Engineering University, 1989; 9: 13-17. (in Chinese)

[29] Li S Y. Virtual optimization on walking tractor x type seat. Nanning: Guangxi University, 2005. (in Chinese)

[30] Xu X M, Zhu S H. A shear type seat vibration theory analysis. Vehicle Application Engineering, 2003; 16: 1659-1663. (in Chinese)

[31] $\mathrm{Xu} \mathrm{X} \mathrm{M,} \mathrm{Zhu} \mathrm{S} \mathrm{H.} \mathrm{Research} \mathrm{on} \mathrm{static} \mathrm{and} \mathrm{dynamic} \mathrm{characteristics}$ simulation of shear seat based on MBS. Mechanical Science and Technology, 2006; 25: 684-686. (in Chinese) 